\title{
Corynebacterium xerosis
}

National Cancer Institute

\section{Source}

National Cancer Institute. Corynebacterium xerosis. NCI Thesaurus. Code C86326.

A species of aerobic or facultatively anaerobic, Gram-positive, coryneform, pleomorphic bacilli assigned to the phylum Actinobacteria. This species is nonmotile, non-spore forming, catalase positive, pyrazinamidase positive, reduces nitrate, urease negative, non-lipophilic, does not hydrolyze esculin or gelatin, and ferments glucose, sucrose and maltose. C. xerosis is commensal to the nasopharynx and skin in humans and is known to cause bacteremia, soft tissue infections, endocarditis, pharyngitis, and pneumonia especially in immunocompromised persons. 